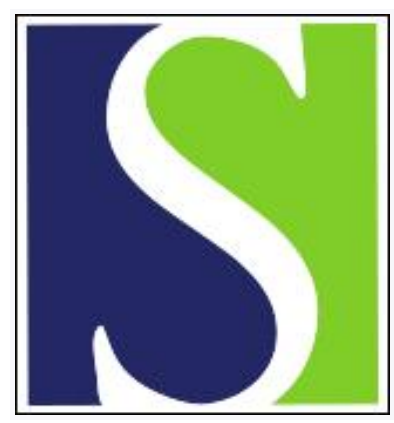

Scand J Work Environ Health 2016;42(1):61-70

https://doi.org/10.5271/sjweh.3530

Published online: 16 Oct 2015, Issue date: 01 Jan 2016

Neurosensory and vascular function after 14 months of military training comprising cold winter conditions

by Carlsson D, Pettersson H, Burström L, Nilsson T, Wahlström J

Results showed a quantifiable impaired neurosensory function and congruent symptom reports after 14 months of winter military training comprising cold winter conditions. The results suggest that prolonged exposure to cold impair sensory nerve function in the hands.

Affiliation: Department of Occupational and Environmental Medicine, Sundsvall Hospital, Sundsvall, SE-851 86 Sweden. daniel.carlsson@lvn.se

Refers to the following text of the Journal: 2009;35(5):384-393

Key terms: cold; cold temperature; cold winter condition; military; military personnel; military training; neurosensory function; old hypersensitivity; sensory threshold; Sweden; vascular function; winter

This article in PubMed: www.ncbi.nlm.nih.gov/pubmed/26473467

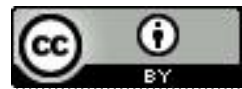




\title{
Neurosensory and vascular function after 14 months of military training comprising cold winter conditions
}

\author{
By Daniel Carlsson, BSc, ${ }^{1}$ Hans Pettersson, PhD, ${ }^{1}$ Lage Burström, PhD, ${ }^{1}$ Tohr Nilsson, PhD, ${ }^{1}$ Jens \\ Wahlström, PhD, ${ }^{1}$
}

\begin{abstract}
Carlsson D, Pettersson H, Burström L, Nilsson T, Wahlström J. Neurosensory and vascular function after 14 months of military training comprising cold winter conditions. Scand J Work Environ Health. 2016;42(1):61-70. doi:10.5271/sjweh.3530.
\end{abstract}

\begin{abstract}
Objective This study aimed to examine the effects of 14 months of military training comprising cold winter conditions on neurosensory and vascular function in the hands and feet.

Methods Military conscripts $(\mathrm{N}=54)$ were assessed with quantitative sensory testing comprising touch, temperature, and vibration perception thresholds and finger systolic blood pressure (FSBP) after local cooling and a questionnaire on neurosensory and vascular symptoms at both baseline and follow-up. Ambient air temperature was recorded with body-worn temperature loggers.

Results The subjects showed reduced sensitivity to perception of touch, warmth, cold and vibrations in both the hands and feet except from vibrotactile perception in digit two of the right hand (right dig 2). Cold sensations, white fingers, and pain/discomfort when exposed to cold as well as pain increased in both prevalence and severity. There were no statistically significant changes in FSBP after local cooling.

Conclusion Fourteen months of winter military training comprising cold winter conditions reduced sensation from touch, warmth, cold, and vibrotactile stimulus in both hands and feet and increased the severity and prevalence of symptoms and pain. The vascular function in the hands, measured by FSBP after local cooling, was not affected.
\end{abstract}

Key terms cold hypersensitivity; cold temperature; military personnel; neurosensory function; sensory threshold; Sweden

Lifetime prevalence of severe local cold injury in Finland has been estimated at $11 \%$ of the entire population and up to $16 \%$ among those in occupational groups exposed to cold (1). Official statistics from 2013 show that $22 \%$ of all men and $11 \%$ of all women in Sweden are exposed to cold at work for more than 1/4 of their working hours (2). Exposure to cold, often in combination with insufficient coping strategies (ie, clothing), can lead to local cold injuries. Local cold injuries are categorized into freezing cold injuries, occurring at temperatures $<0$ ${ }^{\circ} \mathrm{C}$, and non-freezing cold injuries which occur after prolonged exposure to temperatures $>0{ }^{\circ} \mathrm{C}$ together with wet conditions and local pressure (3). Previous studies have described both short- and long-term sequelae after local cold injury (4-8), the majority of the studies involved military personnel. Remaining sequelae entails neurosensory (cold sensitivity, hypoesthesia, local pain etc), vascular (exaggerated vasospastic reaction to cold stimulus, abnormal skin color etc) $(4,6,7)$, musculoskeletal (stiff and painful joints) (7) or most often a combination of the symptoms stated above. Knowledge derived from prospective studies on how long-term exposure to ambient cold could affect quantifiable neurosensory and vascular function in the limbs is lacking. The term "cold sensitivity" in this study describes an abnormal reaction to cold exposure causing discomfort or the avoidance of cold as suggested by Kay (9).

The aim of this study was to examine the effects on neurosensory and vascular function in the hands and feet after 14 months of military training comprising cold winter conditions. Our hypothesis was that the subjects would suffer from quantifiable impairments in neurosensory and vascular function in the hands and feet as a result of enduring severe cold exposure during the study period.

1 Department of Public Health and Clinical Medicine and Department of Occupational and Environmental Medicine, Sundsvall, Umeå University, Umeå Sweden

Corresponding author: Daniel Carlsson, Department of Occupational and Environmental Medicine, Sundsvall Hospital, Sundsvall, SE-851 86 Sweden [E-mail: daniel.carlsson@1vn.se] 
This has been shown among cold injury victims (8) and since our subjects are exposed to similar repeated tissue cooling and local ischemia (10) similar symptoms could be expected.

\section{Methods}

\section{Study design}

We conducted a prospective study with 14 months followup. Our subjects were military conscripts in the north of Sweden (Arvidsjaur, Norrbotten Regiment I19), called up for 14 months Ranger training from April 2009 to June 2010. Eighty-one gave written consent to participate. At baseline during the first week of training, data on the participants' age, height, weight, tobacco use, previous cold injuries, and earlier vibration exposure were collected. The participants completed a questionnaire and went through a test set of quantitative sensory testing (QST) consisting of thermal perception, thermal pain perception, vibrotactile perception, and touch perception thresholds. A subset of the participants also underwent a finger systolic blood pressure (FSBP) test after local cooling. The number of participants completing each part of the study is shown in figure 1. At follow-up 14 months later, in May/June 2010, 54 of the participants remained in military service. They went through the same QST tests and FSBP and completed the same questionnaire as at baseline with a few additional questions regarding events during their military training. Due to data loss at individual measurement sites, the number of participants included in the analysis differs between the various tests and measurement sites. At follow-up, a specialist in occupational medicine noted the retrospective medical history and performed a physical examination in order to identify possible medical conditions that could affect the results. None were found.
The same test leaders performed all tests at baseline and follow-up with one exception. Two test leaders performed the thermal perception tests at follow-up due to logistical circumstances. Only participants who took part both at baseline and follow-up were included in the analysis.

The Regional Ethical Review Board at the medical faculty at Umeå University, Sweden, approved the study.

\section{Participants}

Ranger training in Arvidsjaur has been considered one of the toughest and most prestigious military trainings in Sweden. Military conscripts enrolled in this training were highly motivated and proclaimed healthy by the Swedish Defense Recruitment Agency prior to enrollment. At baseline, 81 participants attended and 54 remained at follow-up. Participant characteristics at baseline were mean 19.8 [standard deviation (SD) 0.38 ] years, 183.0 (SD 5.0) cm, and 81.4 (SD 8.9) kg. No former cold injuries in the hands or feet or heavy use of hand-arm vibrating tools were reported at baseline. Of the participants, 17 used snuff and 2 smoked. All participants were male.

\section{Cold exposure, cold injury, and tobacco use}

The 14 months ranger training in Arvidsjaur comprised cold winter conditions and included prolonged periods spent in field with no indoor possibilities, full body water immersion in ice-covered waters, outdoor shooting, and physical exercise in cold temperature. To measure ambient temperature, all participants wore a temperature logger (EL-USB-1, Lascar Electronics, Whiteparish, UK) in an open pocket in their combat vest exposed to outdoor air. The temperature logger recorded the temperature continuously every $30^{\text {th }}$ minute during 200 days from November to May covering the cold season. We collected 53 temperature loggers still in service at follow-up. One
Figure 1. Time-line showing the different measurements and the number of participants that completed each part.

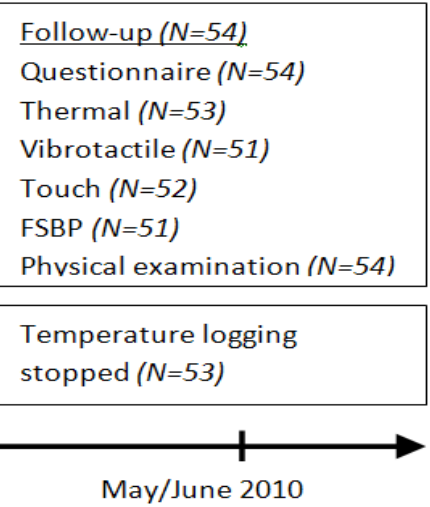

Follow-up $(N=54)$

Questionnaire $(N=54)$

Thermal $(N=53)$

Vibrotactile $(N=51)$

Touch $(N=52)$

Baseline ( $N=81)$

Questionnaire $(N=80)$

Thermal $(N=80)$

Vibrotactile $(N=80)$

Touch $(N=80)$

FSBP $(N=57)$

logging started

$(N=81)$

November 2009

May/June 2010 
participant had lost his logger and among the collected loggers, 3 had not been used at all and 5 had only been used occasionally. Therefore, data from 45 temperature loggers was included in the analysis. The cut-off temperature point for cold exposure used in the analysis was set to $0{ }^{\circ} \mathrm{C}$. All recordings $<0{ }^{\circ} \mathrm{C}$ were considered cold according to findings in a study by Rintamäki et al (11). All participants with temperature measurements that attended both at baseline and follow-up were categorized into three groups based on the $33^{\text {rd }}$ and $66^{\text {th }}$ percentiles for cold exposure. Thus, the cold exposure groups ranged in number of days $<0{ }^{\circ} \mathrm{C}$ from 26.3-39.1 (low) to 39.8-44.6 (medium) to 45.3-58.0 (high).

A cold injury was defined as answering yes to the following question in the follow-up questionnaire "Have you developed frostbite during your military training?" and reporting hand and/or feet as the site of injury. Tobacco users were defined as those using either snuff or smoking at baseline or follow-up.

\section{Quantitative sensory testing}

Touch, thermal, and vibrotactile perception were assessed bilaterally at three sites: the palmar surface of the distal phalanges of the second and fifth finger and on the plantar surface of the first toe. Prior to the testing, the skin temperature was measured to ensure a minimum temperature of $28{ }^{\circ} \mathrm{C}$. If the temperature was lower, the hand and/ or foot were heated by immersion in warm water until the skin temperature reached $28{ }^{\circ} \mathrm{C}$. During the test, the participant was sitting comfortably at a table with the forearm and hand / foot supported in a quiet room.

Touch perception threshold (TT) was assessed using 17 standardized progressively rigid monofilaments (Senselab Aesthesiometer, Somedic AB, Hörby, Sweden), numbered 3-19, calibrated to initiate a bowing at $1.7 \mathrm{~g} / \mathrm{mm}^{2}$ for the thinnest, least rigid monofilament and $137.3 \mathrm{~g} / \mathrm{mm}^{2}$ for the most rigid monofilament. The participant was instructed to close his eyes and report any sensation in the finger or toe by saying "now". Starting with monofilament eight, the monofilament was slowly placed perpendicular on the skin, then bowed during 1-1.5 seconds, held in this position for 1-1.5 seconds and then the bowing was released during 1-1.5 seconds. Lesser rigid monofilaments were applied until the participants could not sense the touch of three consecutive stimuli. If the participant could not sense the first monofilament used, more rigid monofilaments were applied until one was sensed by the participant. Lesser rigid monofilaments were then applied according to the procedure described above. The last monofilament perceived by the participant was recorded as a detection pressure per square millimeter. A higher value indicates reduced sensitivity to touch.

The thermal perception thresholds tested were those for warmth (WT), cold (CT), heat pain (HPT) and cold pain (CPT). Heating and cooling stimuli were delivered with a $2.5 \times 5.0 \mathrm{~cm}$ stimulation probe of Peltier-type (Thermotest ${ }^{\circledR}$, v. 01-S, Somedic AB, Hörby, Sweden). During testing, the participants placed the finger or toe to be tested on the probe with assistance from the test leader and were instructed to exert a similar pressure on the probe for all test sites. Thermal perception thresholds were assessed according to the method-of-limits (12). At the testing, the participant was instructed to press a button as soon as thermal sensations were perceived, thereby causing a temperature read-out by the controlling computer and a return to the neutral probe temperature. Five cold stimuli were consecutively followed by five warmth stimuli, and the thermal thresholds at the site measured was defined as the average of the individual cold and warmth threshold reported by the participant for each stimulus. The test probe neutral temperature was set to $32{ }^{\circ} \mathrm{C}$. Maximum probe temperature was set to $52{ }^{\circ} \mathrm{C}$ and minimum to $10{ }^{\circ} \mathrm{C}$ for reasons of participant safety. Outside these limits, the sensory testing was aborted in accordance with prevailing mandatory hospital safety regulations. The rate of temperature change was set to $1{ }^{\circ} \mathrm{C} / \mathrm{s}$ in the test phase and $3{ }^{\circ} \mathrm{C} / \mathrm{s}$ when the probe returned to the neutral temperature. The thermal perception thresholds are presented as the temperature change in degrees Celsius from neutral temperature to detection temperature. For WT and HPT, a higher value indicates reduced sensitivity to warmth/ heat pain and for CT and CPT a lower value indicates reduced sensitivity to cold/cold pain.

The vibrotactile perception threshold (VT) was assessed with a VibroSense Meter (VibroSense Dynamics AB, Malmö, Sweden). When testing VT, the whorl of the distal phalanx was pressed to a circular metal probe (diameter $4 \mathrm{~mm}$ ) with a contact force of $1 \mathrm{~N}$. Vibration perception thresholds were determined at four frequencies: $8,32,125$ and $500 \mathrm{~Hz}$ according to the von Békésy method, in a manner compliant with the stipulations in the ISO 13091-1 (2001) (13). At the testing, the magnitude of the probe vibration increased gradually. The participant was instructed to press a button as soon as vibrotactile sensations were perceived, thereby causing a vibration magnitude read-out by the controlling computer and a gradual vibration magnitude decrease of the probe. The participant was instructed to release the button when he could no longer perceive vibrotactile sensation, thereby causing another read-out and the vibration magnitude to increase again until next detection. Five increase-decrease cycles were performed for each frequency. An average perception threshold for each frequency was calculated from the last three cycles and the VT for each measured site was calculated as an average of all frequencies combined. The VT is presented as a sensibility index, defined as the ratio between the participant's determined VT and the VT of a reference 
population of the corresponding age and sex. A sensibility index of 1.0 indicates a VT equivalent to those of the reference population. A lower value indicates reduced sensitivity to vibration stimulus and a sensibility index lower than 0.8 is considered abnormal (14).

\section{Finger systolic blood pressure after local cooling}

The systolic blood pressure of digits (dig) 1-5 on the right hand were continuously measured using strain gauge plethysmography (HV Lab Multi-Channel Plethysmograph, IVSR, University of Southampton, UK) according with International Standard ISO 14835-2 (2005) (15). Double-inlet cuffs were put on the middle phalanges of each finger. Strain gauges were attached at the distal phalanges of all fingers. During the test, the participants were laying down in a supine position with their right arm fully supported with the fingers lying free in the air. The temperature in the room where the testing was performed ranged from $17-22^{\circ} \mathrm{C}$.

The cuff around dig 1 was filled with air to serve as a reference finger and the cuffs around dig $2-4$ were filled with water. Dig 2-4 were then simultaneously thermostated three times with pressurized water circulating at 30 ${ }^{\circ} \mathrm{C}, 20^{\circ} \mathrm{C}$ and $10{ }^{\circ} \mathrm{C}$, respectively, for five minutes each. All cuffs were pressurized to a suprasystolic level to obtain ischemia during cooling. The pressure in all cuffs was then reduced at $2 \mathrm{mmHg} / \mathrm{s}$ and the cuff-pressure for each finger was registered as the finger systolic blood pressure (FSBP) when the blood circulation rapidly returned. The $\%$ FSBP was calculated as the FSBP at $20^{\circ} \mathrm{C}$ and $10^{\circ} \mathrm{C}$ percentage of FSBP at $30^{\circ} \mathrm{C}$ in the same finger corrected for the change of pressure in the reference finger during the examination according to the following formula:

$$
\begin{aligned}
& \% \mathrm{FSBP}_{10^{\circ} \text { or } 20^{\circ}}=\left(\mathrm{FSBP}_{10^{\circ} \text { or } 20^{\circ}} \times 100\right) /\left(\mathrm{FSBP}_{30^{\circ}}-\right. \\
& \left.\left(\mathrm{FSBP}_{\text {ref } 30^{\circ}}-\mathrm{FSBP}_{\text {ref, } 10^{\circ} \text { or } 20^{\circ}}\right)\right) \text {. }
\end{aligned}
$$

A $\%$ FSBP value $<100 \%$ indicates an increased vasospastic reaction to local finger cooling.

\section{Pain, vascular and neurosensory symptom assessments}

Pain ratings and vascular and neurosensory symptoms were assessed by a questionnaire at baseline and followup. Pain ratings were made on an 11-point pain intensity numeric rating scale, with $0=$ "no pain" and $10=$ "pain as bad as it could be" (16). The perceived pain intensity was assessed by a question asking for the "average pain in the hands/fingers and feet/toes during the past month". The questions regarding vascular and neurosensory symptoms were: (i) "Do you have a sensation of cold in your hands/fingers and feet/toes?"; (ii) "Do you have white (pale) fingers and toes of the type that appear when exposed to damp and cold weather?" (17); (iii) "Do you experience pain/discomfort when exposed to cold?" The symptoms were assessed from a 4-category response scale, comprising: "no", "insignificant", "somewhat" and "quite a lot". The categories were transformed to an ordinal scale from 1-4 before analyses.

\section{Analyses}

The Shapiro-Wilk test and histogram was used to control the difference between baseline and follow-up in QST and FSBP for normality. Variables meeting normality were HPT, CPT, VT, and FSBP. Variables not meeting normality were TT, WT, and CT. Paired t-tests were used to analyze the changes in normally distributed variables, and Wilcoxon signed-rank tests were used for analyzing changes in non-normal distributed variables. The analyses were made separately for each measurement site, each type of stimulus, and in FSBP separately for the provocation test at $10{ }^{\circ} \mathrm{C}$ and $20^{\circ} \mathrm{C}$. Wilcoxon signed-rank test was used to analyze the difference between baseline and follow-up in "sensation of cold", "white fingers", and "pain/discomfort when exposed to cold" and pain in hands and feet. Possible influence of cold exposure (ie, total time $<0{ }^{\circ} \mathrm{C}$ ), tobacco use, or self-reported cold injury during military training, was tested by one-way ANOVA with changes in QST findings (TT, WT, CT, HPT, CPT, VT) or FSBP as the dependent variable. Levine's test was used to control for homogeneity of variance in each group.

Repeated measurement ANOVA was used to test the possible influence of different test leaders in assessments of thermal thresholds at follow-up. Test-leader, time and the interaction between these two factors were analyzed.

All statistical analyses were performed with IBM SPSS Statistics for Windows (version 20.0, IBM Corp, Armonk. NY, USA) and P-values $<0.05$ were considered statistically significant.

\section{Results}

\section{Lost to follow-up}

Of the 81 participants, 27 quit the military training prematurely and thus did not attend the follow-up. A specialist in occupational medicine interviewed 20 by phone to assess reasons for drop-out which were musculoskeletal injury $(\mathrm{N}=9)$ and psychological reasons $(\mathrm{N}=11)$. The drop-outs did not perform differently compared to the remaining participants in any of the baseline measurements $(\mathrm{P}>0.05)$.

\section{Cold exposure}

From November to May, the participants were exposed to temperatures $<0{ }^{\circ} \mathrm{C}$ for an average of 42 days (table 
1). The lowest temperature registered within the group was $-30{ }^{\circ} \mathrm{C}$ and temperatures $<0^{\circ} \mathrm{C}$ were recorded every month. The maximum number of days in succession any participant spent in temperatures $<0{ }^{\circ} \mathrm{C}$ was 14.5 days.

\section{Quantitative sensory testing}

There was a statistically significant reduced sensitivity in TT, WT and CT in both hands and feet for all measurement sites between baseline and follow-up, except for VT in dig 2 in the right hand. For HPT and CPT, there was no consistent pattern regarding changes between baseline and follow-up (figures 2 and 3, table 2 ). The reduced sensitivity was not significantly associated with tobacco use or cold exposure. However, participants that reported a cold injury during the military training $(\mathrm{N}=8)$, had reduced sensitivity $(\mathrm{P}<0.05)$ compared to the non-injured group in 5 out of 8 thermal perception tests (WT in the right dig 2 and 5 and left dig 5 and for CT left dig 2 and 5.)

Table 1. Number of days spent in ambient temperatures presented as mean values and standard deviation (SD).

\begin{tabular}{lcrc}
\hline \multirow{2}{*}{$\begin{array}{l}\text { Temperature } \\
\left({ }^{\circ} \mathrm{C}\right)\end{array}$} & \multicolumn{2}{c}{ Total number of days } & \multirow{2}{*}{$\begin{array}{c}\text { Number of days in } \\
\text { succession (range) }\end{array}$} \\
\cline { 2 - 3 } & Group mean & SD & \\
\hline$<10$ & 58.8 & 11.6 & $9.9-25.5$ \\
$<0$ & 41.9 & 8.3 & $2.4-14.5$ \\
$<-10$ & 11.7 & 2.9 & $0.8-7.1$ \\
\hline
\end{tabular}

Finger systolic blood pressure after local cooling

The \% FSBP did not change statistically significant between baseline and follow-up for any digit or at any provocation temperature (table 2). No consistent pattern regarding changes in the average \% FSBP could be identified.

\section{Vascular and neurosensory symptoms and pain}

There was a statistically significant increase from baseline to follow-up in severity of all self-reported symptoms investigated in both hands and feet: "sensation of cold" ( $\mathrm{P}<0.001-0.001)$, "white fingers" $(\mathrm{P}<0.001)$ and "pain/discomfort when exposed to cold" $(\mathrm{P}<0.001)$ (figure 4). The number of participants reporting any of the two most severe categories ("somewhat" or "quite a lot") of symptoms in the hands had increased from 2 to 12 for "sensation of cold", from 2 to 18 for "white fingers" and from 2 to 26 for "pain/discomfort when exposed to cold".

A similar pattern was observed for the feet with an increase from 1 to 12 for "sensation of cold", from 2 to 18 for "white toes" and from 0 to 22 for "pain/discomfort when exposed to cold".

The average pain rating during last month increased in both hands $(\mathrm{P}<0.001)$ and feet $(\mathrm{P}=0.002)$ from baseline to follow-up. The number of participants reporting any average pain during the last month $(>0)$ increased from 7 to 29 in the hands and from 9 to 25 in the feet.

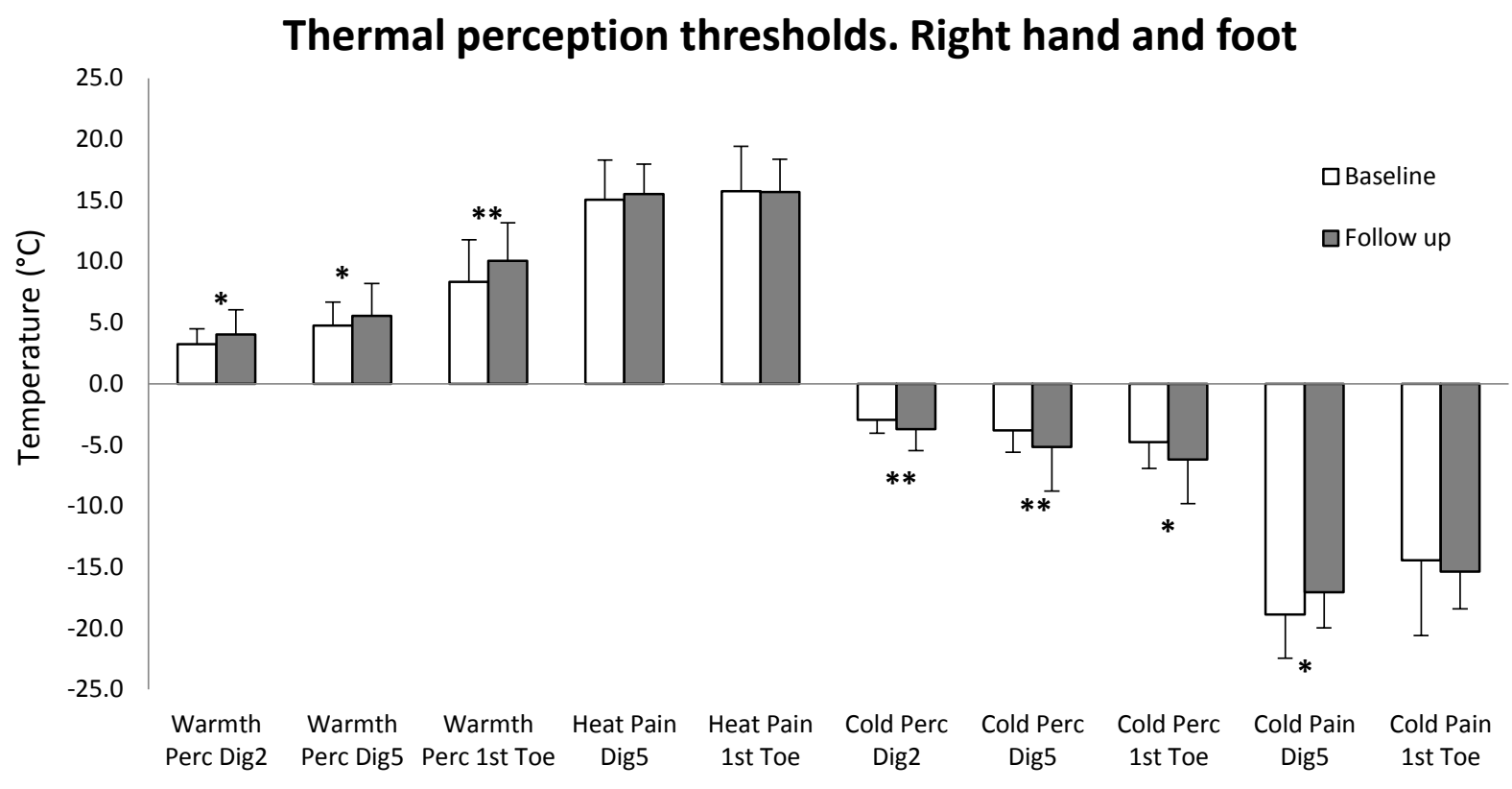

Figure 2. Perception (perc) thresholds for warmth, heat pain, cold and cold pain at baseline and follow-up for the right digit (dig) 2 , dig 5 and first toe presented as the mean difference from neutral temperature to detection temperature with standard deviation bars. ${ }^{*} P<0.05 ;{ }^{* *} P<0.01$. 


\section{Vibrotactile perception threshold}

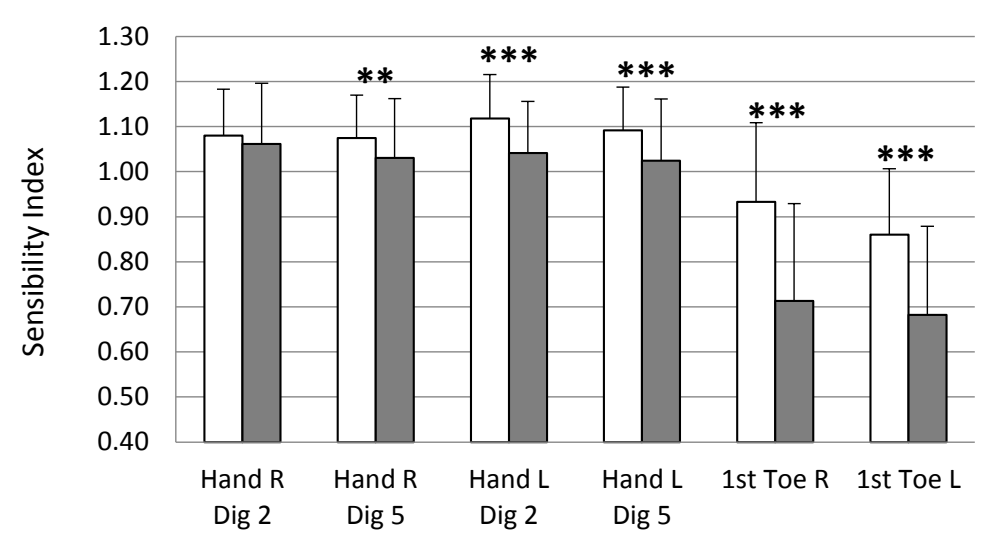

Figure 3. Vibrotactile perception thresholds for digit (dig) 2, dig 5 and the first toe on the right (R) and left $(L)$ side presented as the mean sensibility index at baseline and follow-up with standard deviation bars. ${ }^{* \star} \mathrm{P}<0.01 ;{ }^{* * *} \mathrm{P}<0.001$.
The proportion of participants that increased their pain rating for the average pain during last month was $49 \%$ for hand pain and $40 \%$ for foot pain.

\section{Cold injury}

At follow-up, ten participants reported they had suffered from a cold injury during military training. The cold injuries reported were hands $(\mathrm{N}=2)$, feet $(\mathrm{N}=2)$, hands and feet $(\mathrm{N}=4)$ and face/chins $(\mathrm{N}=2)$. The severity of the cold injuries are unknown. The eight participants that had suffered from cold injury in their hands and/or feet were included in the corresponding analysis.

\section{Discussion}

The main findings were reduced sensitivity for touch, warmth, cold, and vibrotactile stimulus in both hands and feet after 14 months of military training comprising cold winter conditions. Pain/discomfort when exposed to cold, self-reported sensation of cold, and white fingers were more severe at follow-up compared to baseline. Pain in the hands and feet were also more prevalent and had a higher intensity at follow-up. To our knowledge this is the first prospective study investigating the effects of winter-time cold exposure on neurosensory and vascular function in hands and feet. Previous studies have either studied sequelae after cold injury (4-8) or rewarming responses and heart rate variability after cold exposure $(18,19)$. Most comparisons to other studies in this section will therefore be made to studies on cold injuries and not cold exposure.

\section{Quantitative sensory testing}

Quantitative sensory testing examines the sensory unit after application of different mechanical or thermal stimuli of controlled intensity. Both large (A-beta) and small (A-delta and a subset of C) nerve fibers, including the corresponding central pathways are assessed (20). Quantitative sensory testing is considered suitable for neurological disorders affecting the small fiber sensory units in the extremities (21).

The sensation of temperature is mainly transmitted by A-delta and C fibers and the sensation of touch and vibration is mainly transmitted by A-beta fibers. The reduced sensitivity in WT and CT indicate a possible effect on small fiber peripheral nerves and the reduced sensitivity in TT and VT suggest involvement of larger nerve fibers as well. The magnitude of the mean reduction from baseline to follow-up were relatively small. In $\mathrm{WT}$, the mean reduction ranged from $0.8-1.9^{\circ} \mathrm{C}$ and, for $\mathrm{CT}$, the range was $0.8-1.4^{\circ} \mathrm{C}$. For VT, the group mean of the sensibility index was still $>1.0$ at follow-up, even though a statistically significant reduction had occurred compared to baseline. These values would be considered normal in a clinical setting where the cut-off for abnormally reduced sensitivity to WT or CT is normally 2 SD lower than a mean reference value and a sensibility index of $<0.80$ for VPT is acceptable (14). There is however congruence between QST findings and subjective symptom descriptions in this study, which supports the idea that our QST findings are of clinical value. In a previous study, we observed a similar QST pattern among military conscripts who suffered from cold injuries and were enrolled in the same type of training as the current study population (8).

\section{Finger systolic blood pressure after local cooling}

The \% FSBP value was not affected during the study period. Previous studies have focused on cold injuries and found an increasing vasospastic reaction and prevalence of white fingers $(4,8)$. A possible explanation is that one winter of cold exposure might not be sufficient 
Table 2. Touch perception thresholds (presented as pressure in $\mathrm{g} / \mathrm{mm}^{2}$ ), thermal perception thresholds (warmth, heat pain, cold and cold pain; presented as the mean difference in degrees Celsius from neutral temperature to detection temperature). Vibrotactile perception thresholds (presented as the sensibility index), and finger systolic blood pressure (FSBP). [ $95 \% \mathrm{Cl}=95 \%$ confidence interval.]

\begin{tabular}{|c|c|c|c|c|c|c|c|c|c|}
\hline & & \multicolumn{3}{|c|}{ Baseline } & \multicolumn{2}{|c|}{ Follow up } & \multicolumn{2}{|c|}{ Difference } & \multirow[b]{2}{*}{ P-value } \\
\hline & & $N$ & Mean & $95 \% \mathrm{Cl}$ & Mean & $95 \% \mathrm{Cl}$ & Mean & $95 \% \mathrm{Cl}$ & \\
\hline \multicolumn{10}{|c|}{ Perception } \\
\hline \multicolumn{10}{|c|}{ Touch } \\
\hline \multirow[t]{2}{*}{ Digit 2} & Right & 52 & 8.06 & $7.35-8.76$ & 12.5 & $11.5-13.6$ & 4.46 & $3.29-5.63$ & $<0.001$ \\
\hline & Left & 52 & 8.85 & $8.08-9.61$ & 12.2 & $11.2-13.2$ & 3.35 & $2.15-4.54$ & $<0.001$ \\
\hline \multirow[t]{2}{*}{ Digit 5} & Right & 52 & 6.46 & $5.91-7.01$ & 9.65 & $8.86-10.5$ & 3.19 & $2.43-3.95$ & $<0.001$ \\
\hline & Left & 52 & 6.62 & $5.94-7.29$ & 9.88 & $9.02-10.7$ & 3.27 & $2.30-4.24$ & $<0.001$ \\
\hline \multirow[t]{2}{*}{ 1st Toe } & Right & 52 & 17.0 & $14.2-19.8$ & 41.5 & $33.3-49.6$ & 24.5 & $16.0-33.0$ & $<0.001$ \\
\hline & Left & 52 & 14.9 & $12.4-17.4$ & 43.3 & $33.6-53.1$ & 28.4 & $18.7-38.2$ & $<0.001$ \\
\hline \multicolumn{10}{|l|}{ Warmth } \\
\hline \multirow[t]{2}{*}{ Digit 2} & Right & 53 & 3.3 & $2.9-3.6$ & 4.0 & $3.5-4.6$ & 0.8 & $0.2-1.3$ & 0.023 \\
\hline & Left & 52 & 3.5 & $3.1-3.9$ & 4.8 & $4.0-5.7$ & 1.3 & $0.6-2.1$ & 0.001 \\
\hline \multirow[t]{2}{*}{ Digit 5} & Right & 52 & 4.8 & $4.2-5.3$ & 5.6 & $4.8-6.3$ & 0.8 & $0.2-1.4$ & 0.020 \\
\hline & Left & 51 & 4.6 & $4.0-5.2$ & 5.8 & $4.9-6.6$ & 1.1 & 0.41 .9 & 0.005 \\
\hline \multirow[t]{2}{*}{ 1st Toe } & Right & 52 & 8.3 & $7.4-9.3$ & 10.1 & $9.2-10.9$ & 1.7 & $0.7-2.7$ & 0.004 \\
\hline & Left & 51 & 8.8 & $7.9-9.7$ & 10.7 & $9.7-11.6$ & 1.9 & $0.9-2.8$ & $<0.001$ \\
\hline \multicolumn{10}{|l|}{ Cold } \\
\hline \multirow[t]{2}{*}{ Digit 2} & Right & 53 & 2.9 & $2.6-3.2$ & 3.7 & $3.2-4.2$ & 0.8 & $0.3-1.3$ & 0.006 \\
\hline & Left & 53 & 2.7 & $2.3-3.0$ & 4.1 & $3.2-5.0$ & 1.4 & $0.6-2.3$ & 0.001 \\
\hline \multirow[t]{2}{*}{ Digit 5} & Right & 52 & 3.8 & 3.3-4.3 & 5.2 & $4.2-6.2$ & 1.4 & $0.4-2.3$ & 0.009 \\
\hline & Left & 51 & 3.3 & $2.8-3.7$ & 4.5 & $3.8-5.2$ & 1.2 & $0.5-2.0$ & 0.001 \\
\hline \multirow[t]{2}{*}{ 1st Toe } & Right & 53 & 4.8 & $4.2-5.4$ & 6.2 & $5.2-7.2$ & 1.4 & $0.3-2.5$ & 0.019 \\
\hline & Left & 53 & 4.8 & $4.2-5.3$ & 6.0 & $5.1-6.8$ & 1.2 & $0.4-2.0$ & 0.005 \\
\hline \multicolumn{10}{|l|}{ Heat pain } \\
\hline Digit 5 & Right & 47 & 15.1 & $14.1-16.0$ & 15.5 & $14.8-16.2$ & 0.4 & $-0.5-1.4$ & 0.35 \\
\hline & Left & 47 & 14.7 & $13.7-15.7$ & 15.3 & $14.6-16.1$ & 0.6 & $-0.3-1.5$ & 0.172 \\
\hline 1st Toe & Right & 40 & 15.8 & $14.6-16.9$ & 15.7 & $14.8-16.6$ & -0.1 & $-1.2-1.1$ & 0.889 \\
\hline & Left & 39 & 15.4 & $14.3-16.5$ & 16.2 & $15.5-16.9$ & 0.8 & $-0.3-1.9$ & 0.167 \\
\hline Cold pair & & & & & & & & & \\
\hline Digit 5 & Right & 14 & 18.9 & $16.8-20.9$ & 17.0 & $15.4-18.7$ & -1.8 & $-4.1-0.4$ & 0.1 \\
\hline & Left & 20 & 17.9 & $16.0-19.8$ & 15.6 & $14.0-17.1$ & -2.3 & $-4.5--0.2$ & 0.035 \\
\hline 1st Toe & Right & 20 & 14.4 & $11.5-17.3$ & 15.3 & $13.9-16.8$ & 0.9 & $-2.1-4.0$ & 0.532 \\
\hline & Left & 13 & 16.3 & $14.0-18.5$ & 14.3 & $12.7-15.9$ & -2.0 & $-4.3-0.4$ & 0.098 \\
\hline Vibrotact & & & & & & & & & \\
\hline Digit 2 & Right & 51 & 1.08 & $1.05-1.11$ & 1.06 & $1.02-1.10$ & -0.02 & $-0.05-0.01$ & 0.256 \\
\hline & Left & 51 & 1.12 & $1.09-1.15$ & 1.04 & $1.01-1.07$ & -0.08 & $-0.10--0.05$ & $<0.001$ \\
\hline Digit 5 & Right & 51 & 1.07 & $1.05-1.10$ & 1.03 & $0.99-1.07$ & -0.04 & $-0.08--0.01$ & 0.008 \\
\hline & Left & 51 & 1.09 & $1.06-1.12$ & 1.02 & $0.99-1.06$ & -0.07 & $-0.10--0.03$ & $<0.001$ \\
\hline 1st Toe & Right & 50 & 0.93 & $0.88-0.98$ & 0.71 & $0.65-0.77$ & -0.22 & $-0.28--0.16$ & $<0.001$ \\
\hline & Left & 50 & 0.86 & $0.82-0.90$ & 0.68 & $0.63-0.74$ & -0.18 & $-0.23--0.13$ & $<0.001$ \\
\hline$\%$ FSBP & & & & & & & & & \\
\hline $20^{\circ} \mathrm{C}$ & & & & & & & & & \\
\hline Digit 2 & & 39 & 98.1 & $94.1-102.1$ & 99.2 & $95.6-102.8$ & 1.1 & $-3.1-5.3$ & 0.595 \\
\hline Digit 3 & & 38 & 96.7 & $93.0-100.3$ & 100.1 & $97.2-103.0$ & 3.4 & $-0.1-7.0$ & 0.059 \\
\hline Digit 4 & & 39 & 98.2 & $94.6-101.8$ & 98.3 & $94.0-102.5$ & 0.1 & $-4.8-5.0$ & 0.974 \\
\hline Digit 5 & & 37 & 99.7 & $94.8-104.6$ & 95.8 & $91.7-100.0$ & -3.9 & $-9.5-1.8$ & 0.171 \\
\hline $10^{\circ} \mathrm{C}$ & & & & & & & & & \\
\hline Digit 2 & & 39 & 92.5 & $88.9-96.1$ & 90.9 & $87.2-94.5$ & -1.6 & $-6.6-3.4$ & 0.51 \\
\hline Digit 3 & & 37 & 89.9 & $86.6-93.2$ & 90.3 & $86.7-93.9$ & 0.5 & $-4.5-5.4$ & 0.849 \\
\hline Digit 4 & & 39 & 90.5 & $87.0-93.9$ & 92.7 & $89.7-95.6$ & 2.2 & $-1.4-5.8$ & 0.228 \\
\hline Digit 5 & & 37 & 93.8 & $90.0-97.5$ & 93.5 & $90.8-96.2$ & -0.2 & $-4.1-3.6$ & 0.903 \\
\hline
\end{tabular}

to develop an altered vasospastic reaction to cold. It might take a longer duration of cold exposure to affect the FSBP or maybe an altered vasospastic reaction only occurs among persons who suffer from cold injury.

This is the first study to use FSBP after local cooling to examine the effects on blood circulation in the fingers after cold exposure. This is a commonly used method in clinical and epidemiological studies to objectively confirm a subjective history of vibration-induced white fingers and the method is recommended for prospectively monitoring the development of vibration-induced white fingers $(15,22)$. An alternative method for measuring the vasospastic reaction could be the use of a cold-pressor test, immersing the hand in cold water and measuring 
Neurosensory and vascular symptoms in the hands

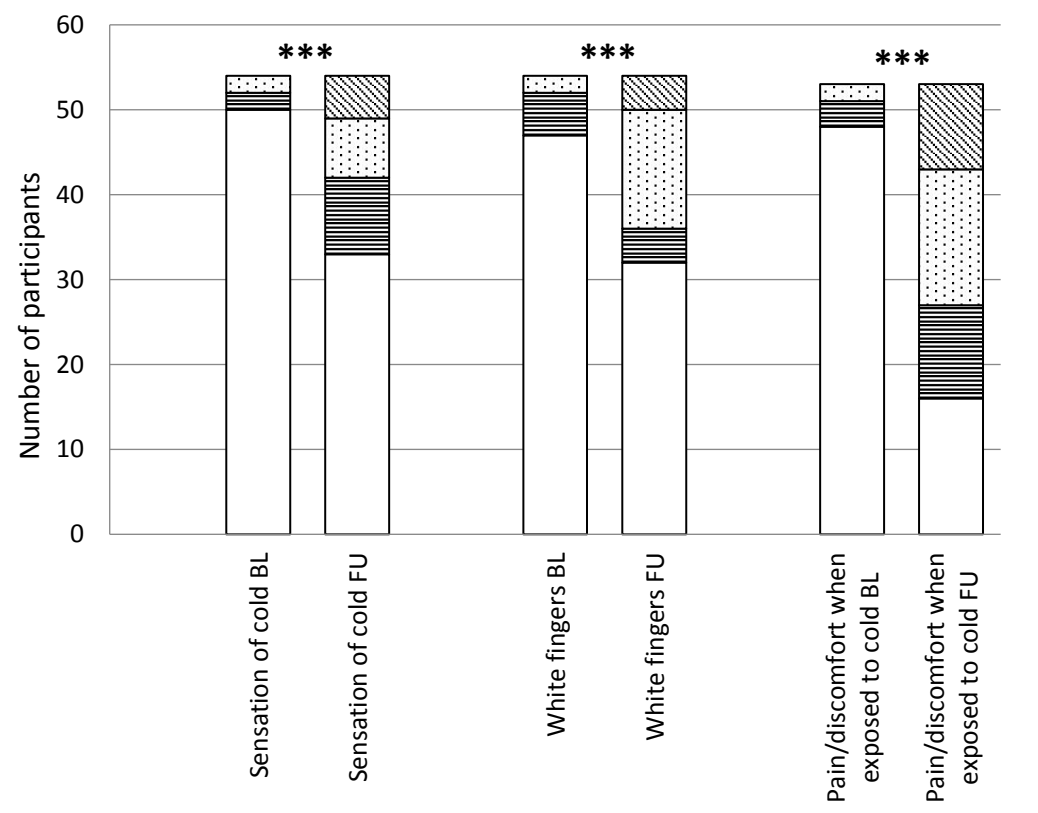

Q Quite a lot

$\square$ Somewhat

目Insignificant

$\square$ No

Figure 4. Prevalence and severity of vascular and neurosensory symptoms in the hands at baseline (BL) and follow-up (FU). ${ }^{* * *} \mathrm{P}<0.001$. the subsequent rewarming of the fingers according to ISO 14835-1 (2005) (23). The cold-pressor test has been proven a reliable method to induce local vasoconstriction (24).

\section{Vascular and neurosensory symptoms and pain}

The increased frequency and intensity of pain and severity of the self-reported neurovascular symptoms "sensation of cold", "white fingers" and "pain/discomfort when exposed to cold" is comparable to the results in an earlier study on the association between cold injuries and these symptoms (8). These are considerable findings since our participants were subjected to cold injuries to a very low extent. The most frequently reported and severe neurosensory symptom was "pain/discomfort when exposed to cold". This is also the symptom most in line with the definition of cold sensitivity, commonly reported among cold injury and persons suffering from hand injuries $(6$, 7, 25-28). The mechanisms of cold sensitivity are still not fully revealed. In their 2014 review, Kambiz et al suggested the involvement of transient receptor potential (TRP) channels. TRP channels are receptors located in free nerve endings that recognize, among other things, thermal and pain stimulus. Six different TRP channels are known to be involved in temperature information channel signaling, of which two have been suggested to be involved in cold sensitivity, namely TRPA1 and TRPM8 (29). The possible involvement of TRP channels in cold sensitivity triggered by cold exposure remains to be studied.

\section{Cold exposure, cold injuries, and tobacco use}

No associations between the magnitude of the reduction in touch, thermal, or vibrotactile sensation and duration of cold exposure, measured by the temperature loggers, were observed. This could possibly be explained by the limited contrast of cold exposure among the subjects. Another possible explanation is that the cold exposure measurements were limited to ambient temperature. Wind, contact cooling, and humidity, all of which are factors contributing to the cold effect, were not taken into account. Cold effect is likely to contribute more to the variables investigated in this study than ambient temperature alone (30).

Participants who reported a cold injury had a more pronounced reduction in the thermal sensitivity in about half of the temperature perception thresholds, which is in line with previous findings (8). The participants with a cold injury did not differ regarding VT or \% FSBP. However, this study was not designed to study effects from cold injuries, and the group suffering from a cold injury was small, thus the results should be interpreted with caution. When excluding the cold-injured participants from analyses of test differences between baseline and follow-up, the associations were still statistically significant in the majority of the WT and CT and all the VT. The tendency towards reduced sensitivity remained for all test sites and stimuli assessed, meaning that the small group of participants with a cold injury could not explain the impairment in neurosensory function or increased rate of symptoms between baseline and follow-up. The weakened association might also be due 
to a smaller study population in the later analyses.

\section{Possible bias}

Since the study was conducted on young male healthy military conscripts, the results may not be applicable on other populations such as women, elderly or unhealthy individuals. To better understand the possible connection between neurosensory and vascular function and cold exposure, an aged-matched control group could have been used. The measurements on FSBP were made on fewer participants than planned due to machinery failure in combination with a limited timeframe with access to the participants. At follow-up, two different test leaders conducted the temperature threshold measurements and this could have biased the results. There are studies showing small differences between raters (good inter-rater reliability) (31) but there are also studies indicating that there might be bias introduced by different raters (32) or different study centers (33). We were able to assess the influence of different raters by using a repeated measure ANOVA. Only the WT for the left first toe (1 out of 12) showed a statistically significant interaction, thus it is not plausible to think that it was the use of different test leaders at follow-up that caused the observed reduced sensitivity for warmth and cold. The participants' current idea of cold exposure is another possible bias regarding the subjective symptoms evoked by cold exposure. It might be that the participants previously had not experienced cold to the same extent as during their military training. This might have influenced them to underestimate and under-report coldtriggered symptoms at baseline compared to follow-up. However, due to the congruent results between the quantitative sensory testing and the subjectively rated symptoms, we do not believe this possible bias to be very significant.

Our results suggest that individuals exposed to cold during several months might risk not only developing a cold injury, as previously known, but also impaired sensory nerve functions, neurosensory and vascular symptoms, and pain. The findings underline the importance of using protective clothing against cold and having the knowledge to handle a cold environment.

In clinical occupational medicine, QST is most frequently used to assess patients exposed to hand-arm vibrations. Our findings identify cold as a possible confounder or effect modifier to QST findings previously considered to be caused by vibration exposure alone.

\section{Concluding remarks}

Fourteen months of winter military training comprising cold winter conditions reduced sensation for touch, warmth, cold, and vibrotactile stimulus in both hands and feet and increased the severity and prevalence of symptoms and pain. The vascular function in the hands, measured by FSBP after local cooling was not affected.

\section{Acknowledgement}

Financial support was provided through regional agreement between Umeå University and the County Councils of Västerbotten and Västernorrland on cooperation in the field of Medicine, Odontology and Health. We gratefully acknowledge Carin From for data collection, Ulla Hjalmarsson for data organization, and Inger Myrberg for drop out interviews. We are also grateful for the generous cooperation of the participating military conscripts as well as officers and staff at the Norrbotten Regiment in Arvidsjaur.

\section{References}

1. Makinen TM, Jokelainen J, Nayha S, Laatikainen T, Jousilahti P, Hassi J. Occurrence of frostbite in the general population--work-related and individual factors. Scand J Work Environ Health. 2009;35:384-93. http://dx.doi.org/10.5271/ sjweh. 1349

2. Swedish Work Environment Authority. Arbetsmiljön 2013 [The Work Environment 2013]. Stockholm (Sweden): Swedish Work Environment Authority. Report no: 2014:3; p469.

3. Imray CH, Richards P, Greeves J, Castellani JW. Nonfreezing cold-induced injuries. J R Army Med Corps. 2011;157:79-84. http://dx.doi.org/10.1136/jramc-157-01-14

4. Ervasti O, Hassi J, Rintamaki H, Virokannas H, Kettunen $\mathrm{P}$, Pramila S, et al. Sequelae of moderate finger frostbite as assessed by subjective sensations, clinical signs, and thermophysiological responses. Int J Circumpolar Health. 2000;59:137-45.

5. Rosen L, Eltvik L, Arvesen A, Stranden E. Local cold injuries sustained during military service in the Norwegian Army. Arctic Med Res. 1991;50:159-65.

6. Ervasti E. Late sequela of the frostbites of the lower extremities (the State Accident Office, Helsinki, the Central Hospital, University of Helsinki and the Kainuu Central Hospital, Finland). Acta Sociomed Scand Suppl. 1972;Suppl 6:269-71.

7. Blair JR, Schatzki R, Orr KD. Sequelae to cold injury in one hundred patients; follow-up study four years after occurrence of cold injury. J Am Med Assoc. 1957;163:1203-8. http://dx.doi.org/10.1001/jama.1957.02970490001001

8. Carlsson D, Burstrom L, Lillieskold VH, Nilsson T, Nordh E, Wahlstrom J. Neurosensory sequelae assessed by thermal and vibrotactile perception thresholds after local cold injury. Int J Circumpolar Health. 2014;73. http://dx.doi.org/10.3402/ijch. v73.23540

Scand J Work Environ Health 2016, vol 42, no 1 
9. Kay S. Venous occlusion plethysmography in patients with cold related symptoms after digital salvage procedures. J Hand Surg Br. 1985;10:151-4. http://dx.doi.org/10.1016/02667681(85)90004-X

10. Weatherley-White RC, Sjostrom B, Paton BC. Experimental Studies in Cold Injury. II. The Pathogenesis of Frostbite. J Surg Res. 1964;4:17-22. http://dx.doi.org/10.1016/S00224804(64)80004-4

11. Rintamaki H, Rissanen S, Mäkinen T, Peitso A. Finger temperatures during military field training at 0 to $-29^{\circ} \mathrm{C}$. J Therm Biol. 2004;29:857-60. http://dx.doi.org/10.1016/j. jtherbio.2004.08.064

12. Hilz MJ, Stemper B, Axelrod FB, Kolodny EH, Neundorfer B. Quantitative thermal perception testing in adults. J Clin Neurophysiol. 1999;16:462-71. http://dx.doi. org/10.1097/00004691-199909000-00008

13. ISO13091-1. Mechanical Vibration-Vibrotactile Perception Thresholds for the Assessment of Nerve Dysfunction-Part 1, Methods of Measurement at the Fingertips. Geneva, Switzerland: International Organisation for Standardisation; 2001.

14. Lundborg G, Dahlin LB, Lundstrom R, Necking LE, Stromberg T. Vibrotactile function of the hand in compression and vibration-induced neuropathy. Sensibility index--a new measure. Scand J Plast Reconstr Surg Hand Surg. 1992;26:2759. http://dx.doi.org/10.3109/02844319209015271

15. ISO14835-2. Mechanical vibration and shock - Cold provocation tests for the assessment of peripheral vascular function - Part 2: Measurement and evaluation of finger systolic blood pressure. Geneva, Switzerland: International Organisation for Standardization; 2005.

16. Von Korff M, Ormel J, Keefe FJ, Dworkin SF. Grading the severity of chronic pain. Pain. 1992;50:133-49. http://dx.doi. org/10.1016/0304-3959(92)90154-4

17. Hagberg M, Burstrom L, Lundstrom R, Nilsson T. Incidence of Raynaud's phenomenon in relation to hand-arm vibration exposure among male workers at an engineering plant a cohort study. J Occup Med Toxicol. 2008;3:13.http://dx.doi. org/10.1186/1745-6673-3-13

18. Brandstrom H, Wiklund U, Karlsson M, Angquist KA, Grip $\mathrm{H}$, Haney M. Autonomic nerve system responses for normal and slow rewarmers after hand cold provocation: effects of long-term cold climate training. Int Arch Occup Environ Health. 2013;86:357-65. http://dx.doi.org/10.1007/s00420012-0767-3

19. Brandstrom H, Grip H, Hallberg P, Gronlund C, Angquist KA, Giesbrecht GG. Hand cold recovery responses before and after 15 months of military training in a cold climate. Aviat Space Environ Med. 2008;79:904-8. http://dx.doi.org/10.3357/ ASEM.1886.2008

20. Heldestad V, Nordh E. Quantified sensory abnormalities in early genetically verified transthyretin amyloid polyneuropathy.
Muscle Nerve. 2007;35:189-95. http://dx.doi.org/10.1002/ mus.20689

21. Lundstrom R. Neurological diagnosis--aspects of quantitative sensory testing methodology in relation to hand-arm vibration syndrome. Int Arch Occup Environ Health. 2002;75:68-77.

22. Bovenzi M, D’Agostin F, Rui F, Negro C. A longitudinal study of finger systolic blood pressure and exposure to hand-transmitted vibration. Int Arch Occup Environ Health. 2008;81:613-23. http://dx.doi.org/10.1007/s00420-0070255-3

23. ISO14835-1. Mechanical vibration and shock - Cold provocation tests for the assessment of peripheral vascular function - Part 1: Measurement and evaluation of finger skin temperature. Geneva, Switzerland: International Organisation for Standardisation; 2005.

24. Feger J, Braune S. Measurement of skin vasoconstrictor response in healthy subjects. Auton Neurosci. 2005;120:88-96. http://dx.doi.org/10.1016/j.autneu.2005.04.004

25. Carlsson IK, Dahlin LB. Self-reported cold sensitivity in patients with traumatic hand injuries or hand-arm vibration syndrome - an eight year follow up. BMC Musculoskelet Disord. 2014;15:83. http://dx.doi.org/10.1186/1471-2474$15-83$

26. Taylor MS, Kulungowski MA, Hamelink JK. Frostbite injuries during winter maneuvers: a long-term disability. Mil Med. 1989;154:411-2.

27. Crouch C, Smith WL. Long term sequelae of frostbite. Pediatr Radiol. 1990;20:365-6. http://dx.doi.org/10.1007/ BF02013182

28. Kurozawa Y, Nasu Y, Hosoda T, Nose T. Long-term followup study on patients with vibration-induced white finger (VWF). J Occup Environ Med. 2002;44:1203-6. http://dx.doi. org/10.1097/00043764-200212000-00017

29. Kambiz S, Duraku LS, Holstege JC, Hovius SE, Ruigrok TJ, Walbeehm ET. Thermo-sensitive TRP channels in peripheral nerve injury: a review of their role in cold intolerance. J Plast Reconstr Aesthet Surg. 2014;67:591-9. http://dx.doi. org/10.1016/j.bjps.2013.12.014

30. Holmer I. Evaluation of cold workplaces: an overview of standards for assessment of cold stress. Ind Health. 2009;47:228-34. http://dx.doi.org/10.2486/indhealth.47.228

31. Moloney NA, Hall TM, O'Sullivan TC, Doody CM. Reliability of thermal quantitative sensory testing of the hand in a cohort of young, healthy adults. Muscle Nerve. 2011;44:547-52. http://dx.doi.org/10.1002/mus.22121

32. Becser N, Sand T, Zwart JA. Reliability of cephalic thermal thresholds in healthy subjects. Cephalalgia. 1998;18:574-82. http://dx.doi.org/10.1046/j.1468-2982.1998.1808574.x

33. Nilsson T, Burstrom L, Hagberg M, Lundstrom R. Thermal perception thresholds among young adults exposed to hand-transmitted vibration. Int Arch Occup Environ Health. 2008;81:519-33. http://dx.doi.org/10.1007/s00420-0070258-0

Received for publication: 9 July 2015 